\title{
Occupation du sol en Valloire de la Préhistoire récente au haut Moyen Âge
}

\section{Guillaume Varennes}

\section{(2) OpenEdition \\ Journals}

Édition électronique

URL : http://journals.openedition.org/adlfi/6782

ISSN : 2114-0502

Éditeur

Ministère de la culture

Référence électronique

Guillaume Varennes, "Occupation du sol en Valloire de la Préhistoire récente au haut Moyen Âge », ADLFI. Archéologie de la France - Informations [En ligne], Rhône-Alpes, mis en ligne le 01 mars 2007. consulté le 26 avril 2019. URL : http://journals.openedition.org/adlfi/6782

Ce document a été généré automatiquement le 26 avril 2019

(C) Ministère de la Culture et de la Communication, CNRS 


\title{
Occupation du sol en Valloire de la Préhistoire récente au haut Moyen Âge
}

\author{
Guillaume Varennes
}

Date de l'opération : 2007 (PT)

1 Les objectifs de la campagne de prospection systématique de 2007 étaient de compléter les fenêtres ouvertes les années précédentes et de couvrir de nouveaux secteurs. Les terrasses de Lapeyrouse et la continuité géologique de la terrasse de Tourdan, au nord et à l'ouest du Dolon, au pied du massif des Bonnevaux, ont été abordés, ainsi que le talweg de Beaurepaire qui a été complété sur la commune de Lapeyrouse-Mornay. Ces fenêtres ont été traitées par deux groupes de travail. Douze jours consacrés à la phase de terrain pour deux groupes de prospection de quatre personnes pour le premier et de six personnes pour le second, ont réalisé une partie des objectifs fixés.

2 Une première équipe a complété durant la première semaine le talweg de Beaurepaire, traité partiellement l'année précédente. L'opération a permis d'apprécier le tissu de petits établissements gallo-romains s'intercalant entre les villae gallo-romaines des Bardelières et des Morelles. On note quelques indices d'occupation protohistorique dans ce secteur. Une nouvelle fenêtre a été ouverte sur la terrasse intermédiaire de Lapeyrouse afin d'en compléter notre couverture, sur les communes de Pact et de LapeyrouseMornay. Cette fenêtre permet d'apprécier un transect nord-sud de la terrasse. Seulement deux établissements antiques ont été appréhendés.

Une fenêtre étudiée par la seconde équipe, est située au nord du Dolon. La prospection de cet espace durant douze jours a permis d'apprécier un faible tissu d'établissements galloromains au débouché du vallon du Dolon et au pied du massif des Bonnevaux, implanté sur les cônes de déjection. Plus à l'ouest, la continuité géologique de la terrasse de Tourdan a livré peu d'indices d'occupation pour les périodes protohistoriques et galloromaines (communes de Moissieu-sur-Dolon, Pisieu et Primarette). 
4 Enfin, au mois d'octobre, une prospection géophysique, employant la méthode ARP (résistivité électrique autotractée), a été mise en place sur le site antique de Tourdan (Revel-Tourdan). Le but de l'opération était de tester la méthode sur le substrat argileux d'origine glaciaire de la terrasse et de recaler en plan les structures découvertes en photographies aériennes, à l'est du bourg actuel. L'opération s'est révélée positive permettant un redressement du probable fanum et de l'enclos fossoyé.

INDEX

operation Prospection thématique (PRT)

Index géographique : Rhône-Alpes, Isère (38), Drôme (26), Primarette, Pisieu, Moissieu-surDolon, Lapeyrouse-Mornay, Pact, Revel-Tourdan

Index chronologique : Empire romain, Protohistoire

\section{AUTEURS}

\section{GUILLAUME VARENNES}

MCC 